\title{
Professor Andreas H. Weiglein (1961-2020): a life dedicated to teach and promote clinical anatomy
}

\author{
Salih Murat Akkın (D) \\ Department of Anatomy, School of Medicine, SANKO University, Gaziantep, Turkey \\ Anatomy 2020;14(1):3-6 @2020 Turkish Society of Anatomy and Clinical Anatomy (TSACA)
}

The world-wide clinical anatomy and plastination communities received the terrible news on February. We lost Univ. Prof. Dr. med. Andreas H. Weiglein, the university lecturer and academic member of the Department of Macroscopic and Clinical Anatomy at Medical University of Graz, in his most productive years, on February 7, 2020 in Graz. As a very good clinical anatomist, Andreas Weiglein had his medical education at the Faculty of Medicine, University of Graz (KarlFranzens-Universität) between 1979 and 1988, graduated with MD degree, and later worked with his renowned masters Prof. Thiel and Prof. Anderhuber at the Institute of Anatomy of the same university. From then on, he was committed to clinical anatomy and trained generations of medical students. The importance of the clinical aspects of anatomy and teaching anatomy in medicine and dentistry always remained at the forefront in his scientific and academic career.

Andreas was one of the honorary members of our society, the Turkish Society of Anatomy \& Clinical Anatomy (TSACA) since 2009 and the member of the scientific advisory board of our journal "Anatomy" since its start in 2007.

I first met with Andreas at the Joint Meeting of the British Association of Clinical Anatomists and the Spanish Anatomical Society organized by Prof. Sanudo at Barcelona in 2002 summer. He assumed the organization duties of EACA congress to be held at Graz one year later. As an academician, who had his heart set on clinical anatomy, he wanted to realize a planning which would be a first in the world. His excitement could be told from his eyes when he was sharing his great enthu-

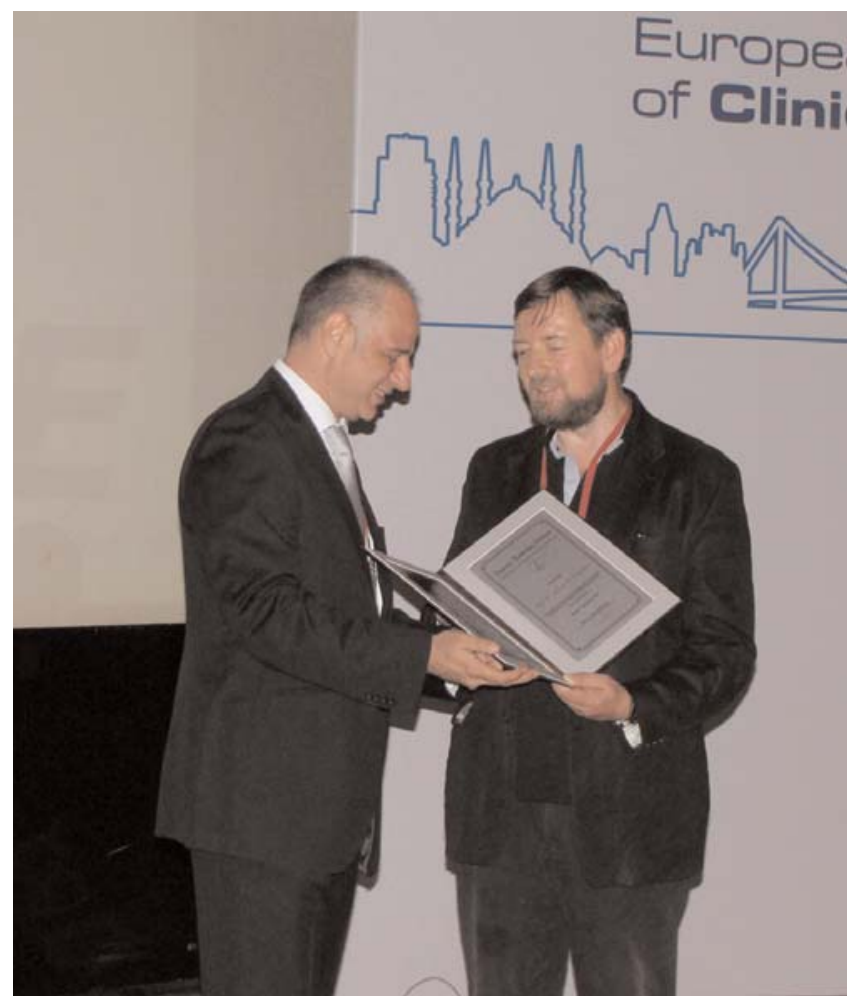

Figure 1. Presenting the honorary membership of TSACA to Andreas $\mathrm{H}$. Weiglein during the opening ceremony at the 10th Congress of EACA held on July 2, 2019 in Istanbul.

siasm. He would draw two great clinical anatomy societies from Europe and the USA together in a congress for the first time. He had the knowledge and experience to achieve his goal, because he had many international contacts in both AACA and EACA thanks to his strenuousness and friendly personality. He also wished many 


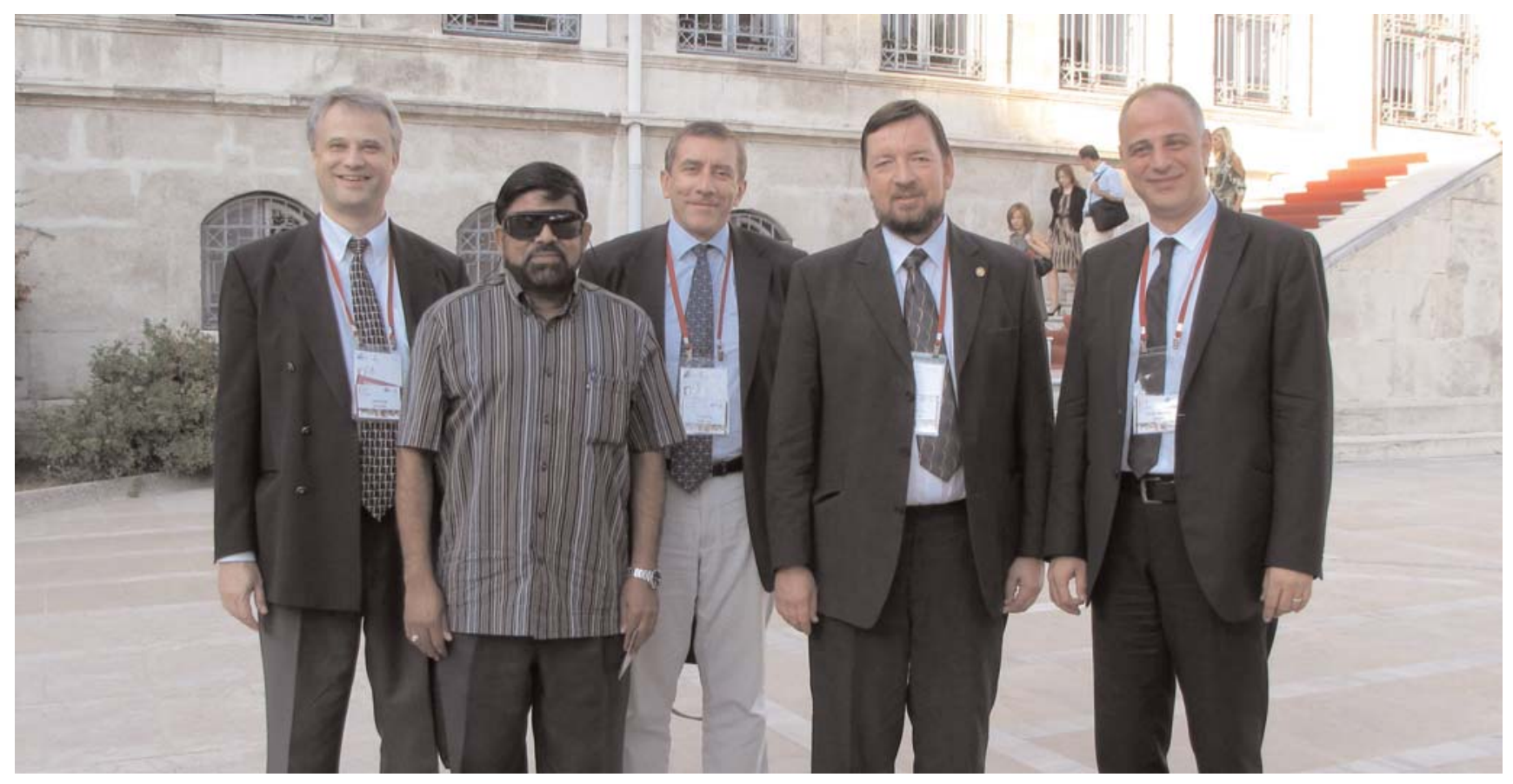

Figure 2. A great moment from the 10th Congress of EACA, 2009, Istanbul. From left to right: Cristian Stefan (USA), Subramaniam Krishnan (Malaysia), Fabrice Duparc (France), Andreas H. Weiglein (Austria) and Salih Murat Akkın (Turkey).

national societies to participate in the congress. In this regard, he offered our society (TSACA), which is known for its potential in the clinical anatomy, to be among the invited societies. We gladly accepted this kind offer.

The 1st Joint Meeting of EACA \& AACA held in Graz on July 2003 was completed successfully in terms of clinical anatomists. Andreas was a great host with all Graz anatomy team as the organizer of the congress, and all participants left Graz with quite positive impressions.

We invited Andreas as one of the keynote speakers to our seventh National Congress held in Diyarbakır in September of the same year. He gladly accepted our invitation. The congress hosted locally by Prof. Hatipoğlu was organized meticulously also to promote the rich history and cultural background of the Southeastern Anatolia. Andreas was amazed at many local characteristics of this region in which he had been for the first time, and made a representation created with the photographs he shot to his colleagues and students when he got back to Graz. Our scientific communication continued in the following years. He participated in our national congresses and made inspiring presentations. With Prof. Anderhuber, he helped young anatomists and students from Turkey to have an opportunity to do researches at the Institute of Anatomy in Graz. At the 10th Congress of EACA that we, as TSACA, assumed and held in Istanbul in 2009, he was the International Congress Coordinator together with Prof. Stephen W. Carmichael from Mayo Clinic, Rochester, MI, USA. Andreas had very substantial contributions to hold the congress successfully with over 400 participants and more than 500 presentations. He was presented the honorary membership of TSACA at this congress.

Andreas was an academician with humanitarian perspectives who believed that there would never be any boundaries in the cooperation among scientists and that all clinical anatomists in the world are the members of a great family. He had a great scientific friendship network from Japan and Malaysia to Brazil and Argentina. He also had close relationship with AACA, and he was the board member of the society. Andreas was a colleague with organizing capabilities. In addition to his position as the vice-chairman of the Institute of Anatomy at Medical University Graz since 1996, he had been the councilor and president of EACA for long years. He was one of the founders and honorary chairman of the International Academy of Clinical Anatomy (IACA). Moreover, he was the chairman of the International Society for Plastination (ISP) between 1997 and 2004, and he made great efforts to increase the scientific quality of the international meetings and the journal of the society. He was awarded with the honorary membership of ISP in 2012 in Beijing. 


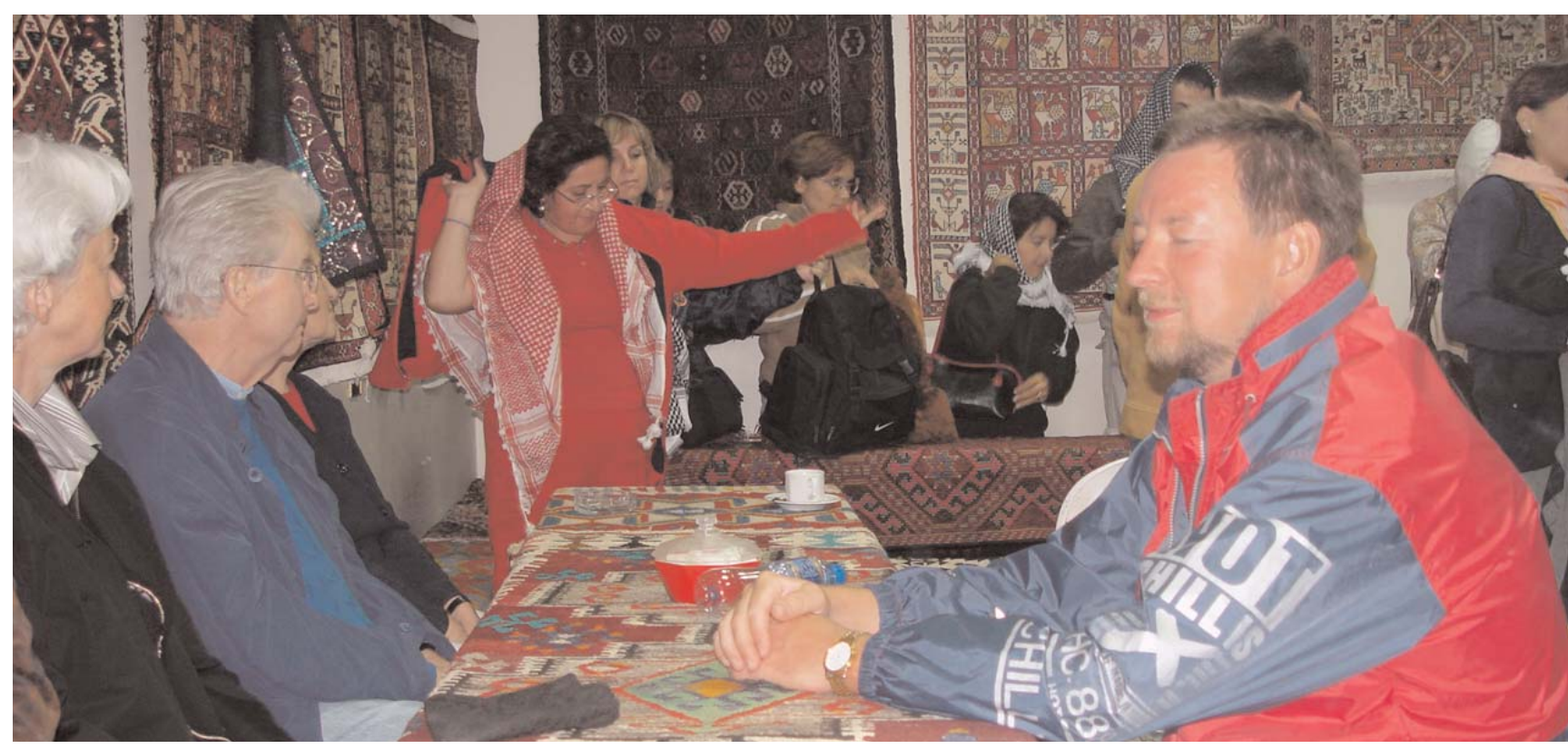

Figure 3. Together with the other participants, Andreas Weiglein in the local cultural atmosphere of Southeastern Anatolia during the social program of the seventh National Congress of TSACA, 2003, Diyarbakır.

Besides our journal "Anatomy", Andreas was a member of the editorial board of several journals such as Anatomical Record, Argentine Journal of Clinical Anatomy, Ars Medica Tomitana, Cells-Tissues-Organs, Clinical Anatomy, Journal of the ISP, and associate edi- tor of Surgical \& Radiologic Anatomy. In addition to the publication of more than 60 papers and 35 textbook chapters, videos and DVDs, he translated and edited the 13th English Edition of the Sobotta Atlas (2005), edited the chapter on the trapezius flaps in Wei/Mardini: Flaps

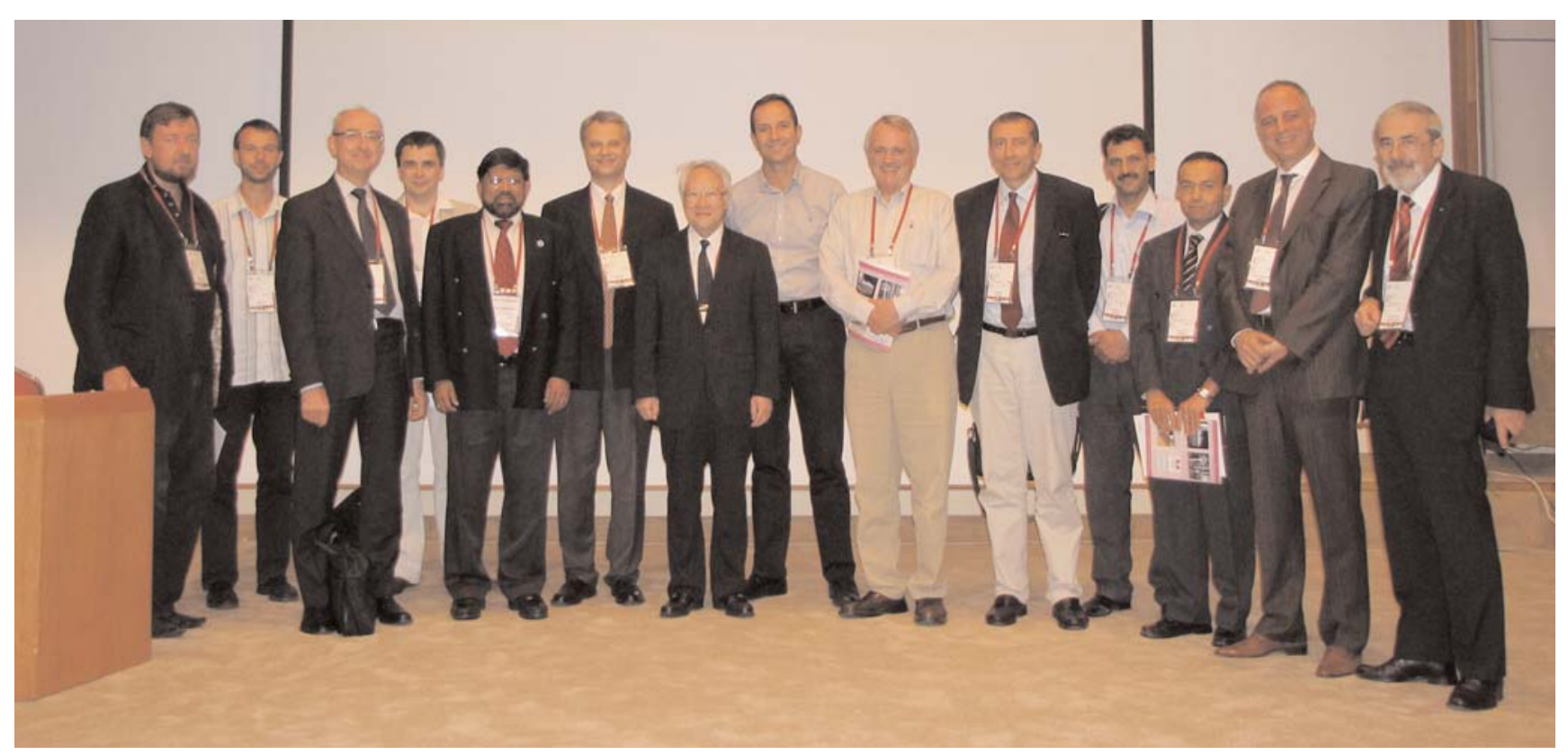

Figure 4. A picture from the General Meeting of IACA, 2009, Istanbul. From left to right: Andreas H. Weiglein (Austria), David Kachlik (former Czech Republic), Christian Fontaine (France), Vaclav Baca (former Czech Republic), Subramaniam Krishnan (Malaysia), Cristian Stefan (USA), Tatsuo Sato (Japan), Deniz Demiryürek (Turkey), Stephen W. Carmichael (USA), Fabrice Duparc (France), a colleague from Egypt, Mustafa Sargon (Turkey), Salih Murat Akkın (Turkey) and Friedrich Anderhuber (Austria). 
(1st ed., 2010), edited the chapter on head and neck in Waldeyer's Anatomie des Menschen (24th ed., 2012) and he was a member of the international advisory board of Netter's Atlas of Anatomy (6th ed., 2012). His research was covering the wide field of clinically applied and radiologic anatomy with special emphasis on the musculoskeletal system, which reflects his clinical training in orthopedic trauma surgery and radiology, and the head and neck regions were of his major interest, as proved by several papers on the temporal bone, the paranasal sinuses, and dental implantology.

Andreas, whom I know as a friend enjoying the life as well as being a good scientist and educator, will always be remembered with his cheerful personality, warmhearted friendship and great efforts to promote clinical anatomy worldwide.
ORCID ID:

S. M. Akkın 0000-0002-5073-1077

deomed.

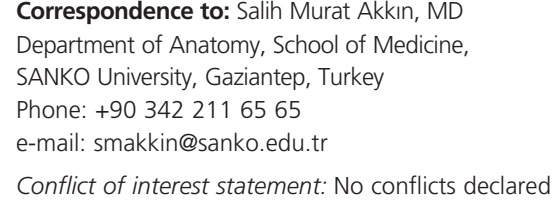

This is an open access article distributed under the terms of the Creative Commons Attribution-NonCommercial-NoDerivs 3.0 Unported (CC BY-NCND3.0) Licence (http://creativecommons.org/licenses/by-nc-nd/3.0/) which permits unrestricted noncommercial use, distribution, and reproduction in any medium, provided the original work is properly cited. Please cite this article as: Akkin SM. Professor Andreas H. Weiglein (1961-2020): a life dedicated to teach and promote clinical anatomy. Anatomy 2020;14(1):3-6. 